THE SURVEY OF THE HIMALAYAN-SINO-TIBETAN SPECIES OF THE GENUS DICEROGASTRA FLETCHER, 1961 (LEPIDOPTERA: NOCTUIDAE, HADENINAE), WITH THE DESCRIPTION OF TWO NEW SPECIES FROM CHINA

\author{
LÁsZló Ronkay ${ }^{1}$, Péter Gyulai² and GÁbor Ronkay ${ }^{3}$ \\ ${ }^{1}$ Department of Zoology, Hungarian Natural History Museum \\ H-1088 Budapest, Baross u. 13, Hungary; E-mail: ronkay@zoo.zoo.nhmus.hu \\ ${ }^{2}$ H-3530 Miskolc, Mélyvölgy u. 13/A, Hungary; E-mail: gyulainegarai.adrienne@upcmail.hu \\ ${ }^{3}$ Heterocera Press Ltd, H-1137 Budapest, Szent István krt. 4, Hungary; \\ E-mail: gaborronkay@gmail.com
}

The taxonomic survey of the Himalayan-Sino-Tibetan species of the hadenine genus Dicerogastra Fletcher, 1961 is given, with the descriptions of two new species, D. euxoides sp. n. and D. jensergabori sp. n., from China. The adults and the genitalia of all four taxa are illustrated. With 29 figures.

Key words: Noctuidae, Hadeninae, Dicerogastra, new species, China.

\title{
INTRODUCTION
}

The genus Dicerogastra Fletcher, 1961 was erected for the East African type species, Miselia proleuca Hampson, 1913. Dicerogastra comprises altogether seven formerly described species, four of which (D. furvilinea (Hampson, 1913), D. proleuca (Hampson, 1913), D. madecassa Viette, 1972 and D. ikondae Berio, 1973) occur in Africa (south of the Sahara and Madagascar); one (D. chersotoides (Wiltshire, 1956)) is distributed from the Levant area (Israel and Jordan) to Saudi Arabia, Oman and Yemen, while the last two species (D. ferrisparsa (Hampson, 1894) and D. costigerodes (Poole, 1989) (= costigera Moore, 1881 nec Walker, 1858) live in the Himalayan region, from Pakistan to Bhutan. The group apomorphy of Dicerogastra is a very conspicuous character in the male genitalia, namely the presence of a group of long, stout spine-like setae originating from the basal section of the harpe (clasper). This feature provides an easy separation of Dicerogastra from the related genera having more or less similar basic structure of the male clasping apparatus (e.g. Sideridis Hübner, [1821], Heliophobus Boisduval, 1828, Odontestra Hampson, 1905, etc.).

This autapomorphic character inspired Hacker (1992) for the description of Haderonidis as a subgenus within the genus Sideridis (type species: Po- 
lia costigerodes). The synonymy of Haderonidis with Dicerogastra was stated by Hreblay and Ronkay (1998), transferring the two known Himalayan species to the latter genus from Sideridis to Dicerogastra.

The eastern Asiatic species of the genus are externally rather similar to each other and are easily distinguished from the members of the SideridisConisania generic complex. The Dicerogastra taxa can be distinguished easily from the externally somewhat similar "Oroplexia" albiflexura (Walker, 1857) (Figs 13-14) due to their strikingly different genitalia and the hairy eyes. Albiflexura belongs, in fact, to the xylenine genus Feliniopsis Roepke, 1938 (Kovács \& Ronkay, in prep.); the genitalia of the holotype are illustrated in Figs 23-24.

The thorough study of the Dicerogastra taxa occurring in the Himalayan region led to the recognition of two undescribed species living in Yunnan and Sichuan in China. Present paper contains the descriptions of these two new species, as well as a proper characterisation of the female genitalia of the Asiatic Dicerogastra taxa.

Abbreviations: BMNH - The Natural History Museum (formerly British Museum, Natural History, London); GYP - genitalia slide of Péter Gyulai; HM - genitalia slide of Márton Hreblay; HNHM - Hungarian Natural History Museum (Budapest, Hungary); PGY - collection of Péter Gyulai; RL - genitalia slide of László Ronkay; ZMHU - Museum für Naturkunde Berlin (Zoological Museum, Humboldt University, Berlin).

\section{SYSTEMATIC PART}

Dicerogastra costigerodes (Poole, 1989)

(Figs 3-6, 17-18, 26)

Polia costigerodes Poole, 1989, Lepidopterorum Catalogus 118(1): 822. An objective replacement name of Agrotis costigera Moore, 1881, nec Walker, 1858. Type locality: [India, Himachal Pradesh] Punjab, Solun. Lectotype: female, in coll. BMNH.

Type material examined - Lectotype female, "Solun, Punjab, Capt. Raed", "Moore Coll., 94-106.", "Lectotype" (blue ringed label); slide No. HM6668f/BM Noct. 15514f (coll. BMNH); paralectotype male, "Cherra Pundi", "coll. Atkinson", “Origin." (pink label), "Agrotis costigera ô type) Moore"; "coll. Staudinger, K. 342.", "1279", "Miselia (Polia) costigera Moore, Boursin det." (coll. ZMHU).

Additional material examined - Nepal. 1 male, Langtang, 1950 m, 1,5 km NE Dhunche, 24.XI.1994, leg. Csorba \& Ronkay, slide No. RL11287m (coll. HNHM); 1 female, Langtang, 2850 m, 3 km SE Syabru, 85²1' E, 2807’ N, 27.IX.1994, leg. G. Csorba \& L. Ronkay, slide No. RL11676f (coll. HNHM); 1 male, Annapurna region, Sudame, 1250 m, 24-26.III.2000, M. Hreblay \& L. Németh, slide No. GYP4373m (coll. PGY); 1 male, Ganesh Himal, Kausing Danda, above Khurpudanda 4100 m, 20-21.IX.1995, leg. P. Gyulai \& A. Garai (coll. PGY); 2 males, Ganesh Himal, 2 km NW of Nesim, 2300 m, 22-23.IX.1995, leg. P. Gyulai \& A. Garai (coll. PGY); 1 male, Ganesh Himal, Gadlang, 2600 m, 22-23.IX.1995, leg. P. Gyulai \& A. Ga- 
rai (coll. PGY); 1 male, Ganesh Himal, Mailungkhala, 1100 m, 25-26.IX.1995, leg. P. Gyulai \& A. Garai (coll. PGY); 1 male, Ganesh Himal, Khalcopkharkha, 3400 m, 17-19.IX.1995, leg. P. Gyulai \& A. Garai (coll. PGY); 1 male, Ganesh Himal, 2 km S of Somdang, 3000 m, 3-4. IV.1995, leg. Gy. M. László \& G. Ronkay (coll. PGY).

Diagnosis - Dicerogastra costigerodes can be distinguished from all other eastern Asiatic congeners by the broad and unicolorous ochreous-beige forewing costal stripe; the costal area of all three other relatives is not or only slightly paler than the median area of the wing, and suffused with variably dark brown-grey. The whitish subterminal line is almost straight at the median veins (between $\mathrm{M}_{1}-\mathrm{M}_{3}$ ) in $D$. costigerodes and $D$. ferrisparsa while this section of the subterminal line is angled inwards in D. euxoides sp. n. and D. jensergabori sp. n., making the subterminal line sinuous in the latter two species. The antemedial and postmedial crosslines are less distinct, less strongly sinuous than in the externally most similar $D$. ferrisparsa and the forewings are somewhat narrower, more elongated, with more pointed apex.

The male genitalia of $D$. costigerodes (Figs 17-18) differ from those of $D$. ferrisparsa (Figs 15-16) by the smaller and more rounded cucullus sitting on longer and straighter neck, much longer pin-like basal setae of harpe, slenderer ampullar process and the rather S-shaped vesica armed by much shorter cornuti field situated medially; from $D$. euxoides by the larger and more rounded cucullus having thinner neck, much shorter and thinner basal setae of harpe, finer, more ventrally projecting ampullar process, and the considerably longer, more medially located cornuti field on the more S-shaped vesica.

The female genitalia of the four Himalayan-Sino-Tibetan Dicerogastra species (Figs 25-29) are rather similar, with clearly recognisable specific differences. The two southern Himalayan species, D. costigerodes and D. ferrisparsa, have shorter antrum, somewhat thickened posterior and longitudinally ribbed anterior part of ductus bursae, and the basal and medial sections of the inner curve of appendix (cervix) bursae is also sclerotised-ribbed (see the Figs 25-26). The specific differences between them are found in the size and shape of these features: $D$. costigerodes has more elongated antrum, less dilated posterior end and shorter but more densely ribbed anterior section of ductus bursae, and the appendix bursae is only basally ribbed, without sclerotised area in the medial part of its inner curve.

In the two Chinese species, the antrum is longer, the ductus bursae is smoothly sclerotised in its entire length, without longitudinal ribs at junction to corpus bursae but with a strong, sclerotised fold, the inner curve of appendix bursae is generally membranous but the apical section may be sclerotised (Figs 27-29).

Distribution - Southern Himalayan. The species is known from India, Nepal and Bhutan. 

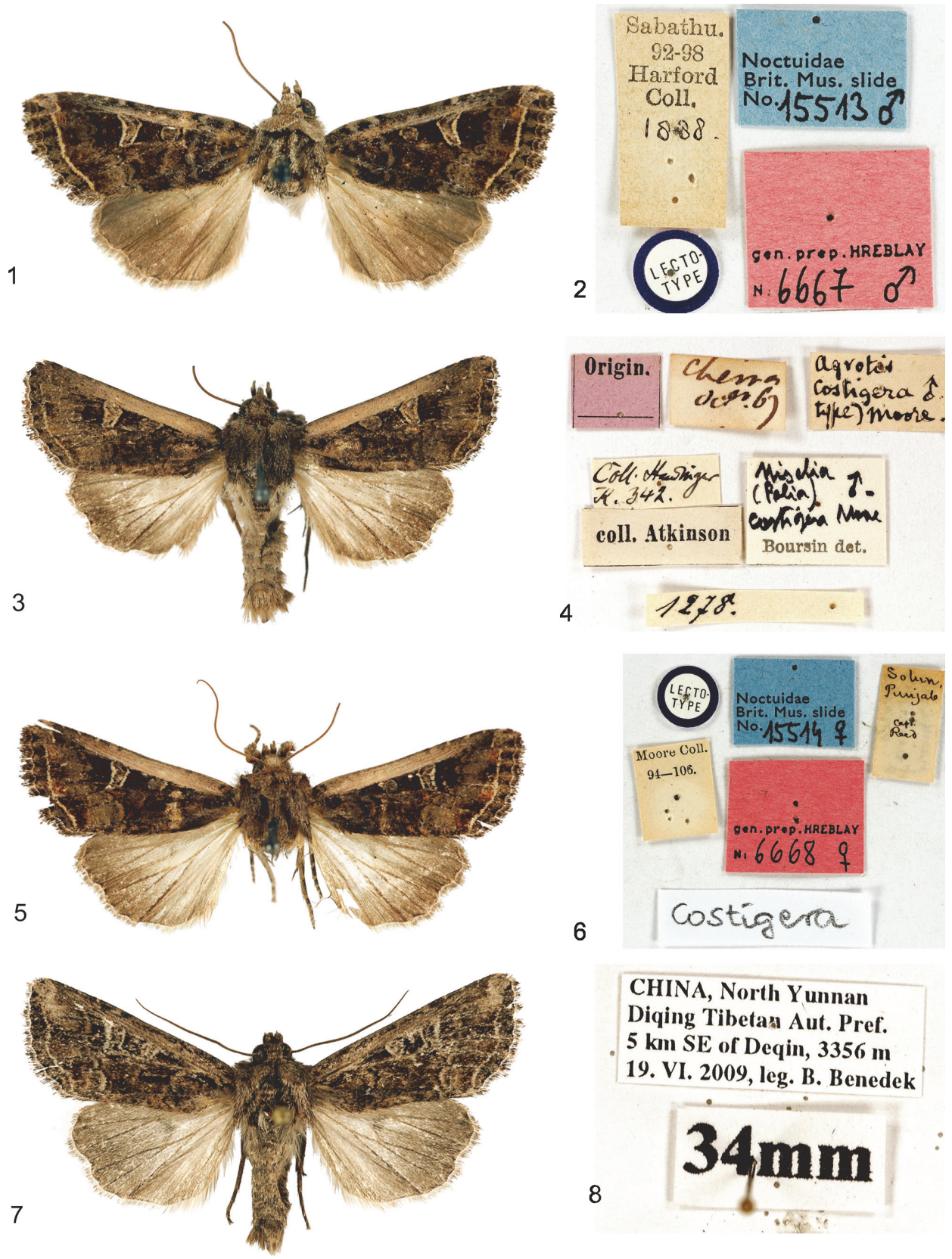

6

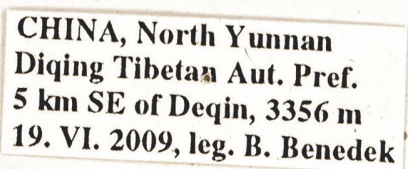

8

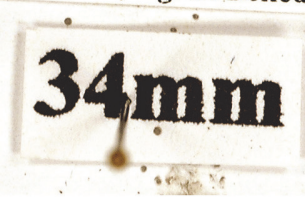

Figs 1-8. Adults of Dicerogastra species. 1-2 = Dicerogastra ferrisparsa (Hampson, 1894), $1=$ lectotype, male $(\mathrm{BMNH}), 2=$ labels of the lectotype; $3-4=$ D. costigerodes (Poole, 1989), $3=$ paralectotype, male $(\mathrm{BMNH}), 4=$ labels of the paralectotype; $5-6=D$. costigerodes (Poole, 1989), 5 = lectotype, female $(\mathrm{BMNH}), 6=$ labels of the lectotype; $7-8=$ D. euxoides sp. $n ., 7=$ holotype, male (GYP); 8 = labels of the holotype 

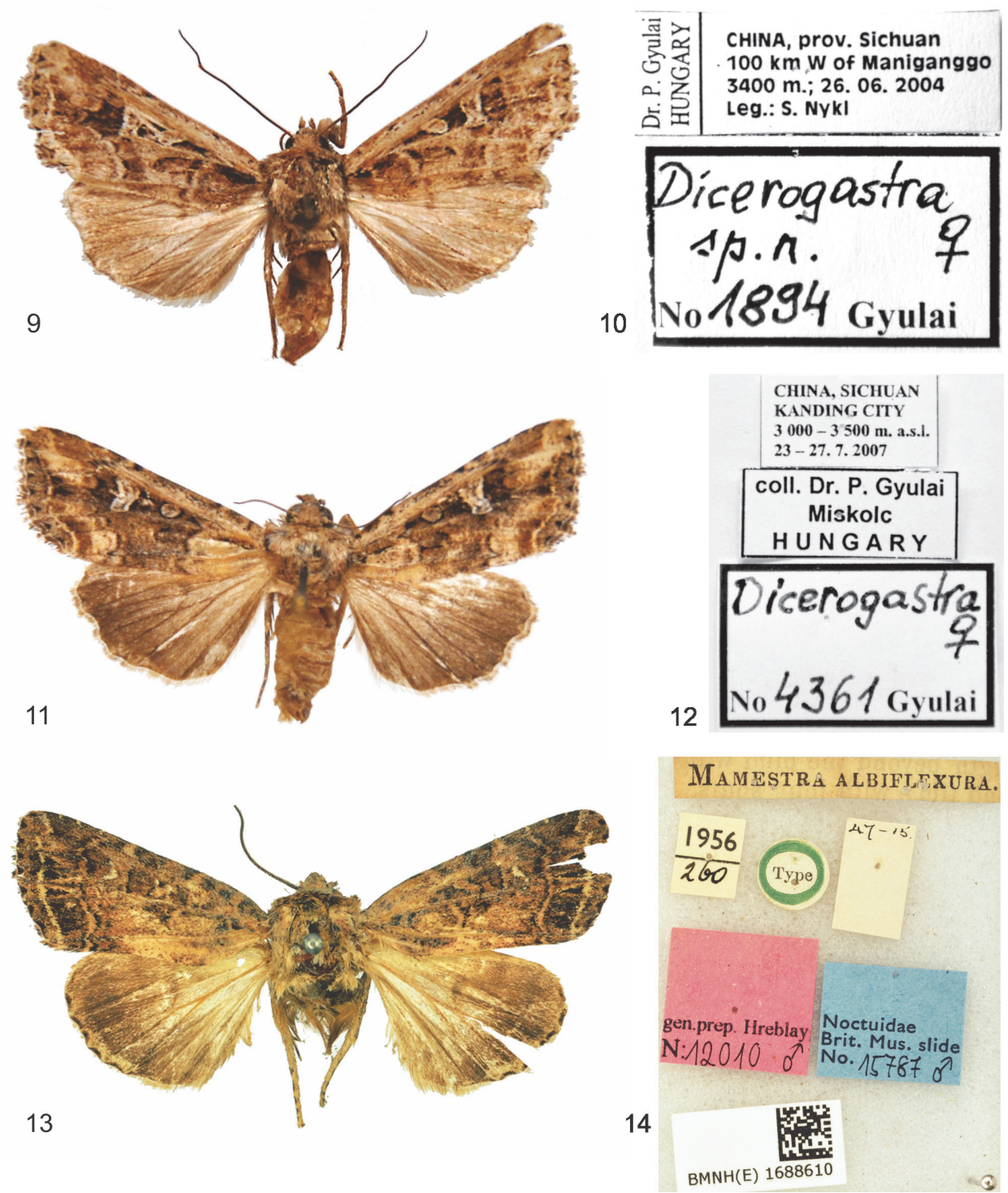

Figs 9-14. Adults of Dicerogastra and Feliniopsis species. 9-10=D. euxoides sp. n., $9=$ paratype, female (GYP), 10 = labels of the paratype; $11-12=D$. jensergabori $\mathrm{sp} . \mathrm{n} ., 11=$ holotype, female (GYP); 12 = labels of the holotype; 13-14 = Feliniopsis albiflexura (Walker, 1857), 13 = holotype, male $(\mathrm{BMNH}) ; 14$ = labels of the holotype 

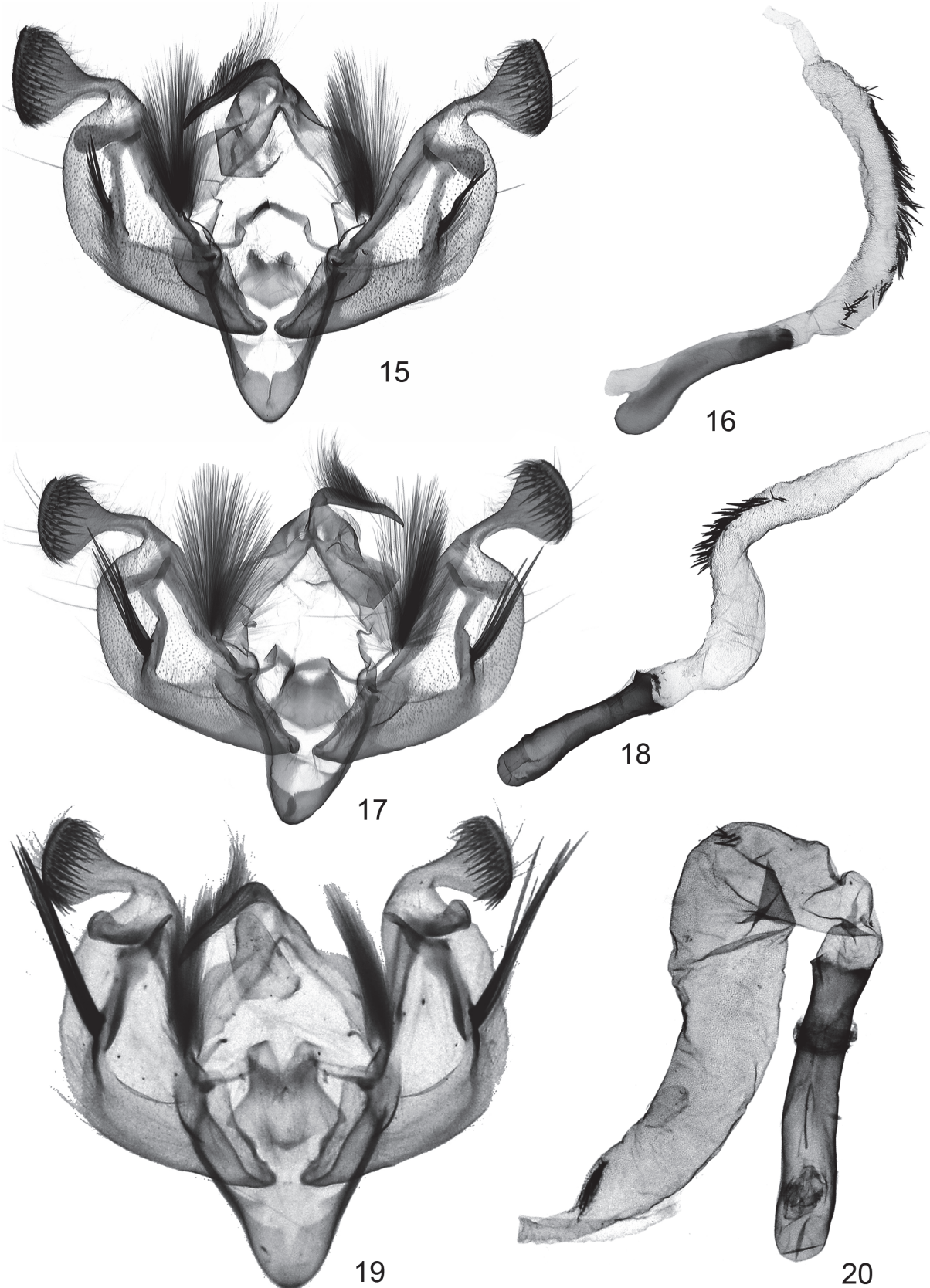

16

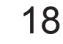

Figs 15-20. Male genitalia of Dicerogastra species. 15-16 = Dicerogastra ferrisparsa (Hampson, 1894), RL11282m, $15=$ clasping apparatus, $16=$ aedeagus; $17-18=D$. costigerodes (Poole, 1989), RL11287m, 17 = clasping apparatus, $18=$ aedeagus; $19-20=D$. euxoides sp. $\mathrm{n}$., holotype, GYP2333m, 19 = clasping apparatus, $20=$ aedeagus 
Dicerogastra ferrisparsa (Hampson, 1894)

(Figs 1-2, 15-16, 25)

Hadena ferrisparsa Hampson, 1894, Moths of British India 2: 201. Type locality: [India] Sabathu. Lectotype: male, in coll. BMNH.

Type material examined - Lectotype male, "Sabathu 92-98., Harford Coll. 1888", "Lectotype" (blue ringed label); slide No. HM6667m/BM Noct 15513m (coll. BMNH).

Additional material examined - Nepal. 1 male, Langtang, 1950 m, 1,5 km NE Dhunche, 24.XI.1994, leg. G. Csorba \& L. Ronkay, slide No. RL11678m (coll. HNHM); 2 males, Langtang, $2850 \mathrm{~m}, 3 \mathrm{~km}$ SE Syabru, $85^{\circ} 21^{\prime} \mathrm{E}, 2^{\circ} 07^{\prime} \mathrm{N}$, 27.IX.1994, leg. G. Csorba \& L. Ronkay, slide Nos RL11282m, RL11680m (coll. HNHM); 1 female, with the same data (coll. PGY); 1 male, 1 female, Ganesh Himal, Gadlang, 2600 m, 22-23.IX.1995, leg. P. Gyulai \& A. Garai, slide Nos GYP4374m, GYP4354f (coll. PGY); 1 male, 1 female, Ganesh Himal, 2 km NW of Nesim, 2300 m, 22-23.IX.1995, leg. P. Gyulai \& A. Garai (coll. PGY); 1 male, Ganesh Himal, Sheplu, 2100 m, 14-15.IX.1995, leg. P. Gyulai \& A. Garai (coll. PGY); 1 male, Ganesh Himal, Khalcopkharkha, 3400 m, 17-19.IX.1995, leg. P. Gyulai \& A. Garai (coll. PGY); 1 female, Ganesh Himal, Kausing Danda, above Khurpudanda 4100 m, 20-21.IX.1995, leg. P. Gyulai \& A. Garai (coll. PGY); 1 female, Ganesh Himal, 2 km S of Somdang, 3000 m, 3-4.IV.1995, leg. Gy. M. László \& G. Ronkay (coll. PGY). Pakistan. 1 male, Kashmir, Himalaya, Mur-

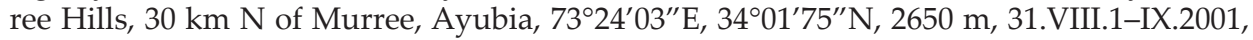
leg. B. Benedek \& G. Ronkay, slide No. RL11677m (coll. HNHM); 1 male, Himalaya Mts, Kaghan valley, Tathabaya, $2300 \mathrm{~m}, 7^{\circ} 27^{\prime} 01^{\prime \prime} \mathrm{E}, 34^{\circ} 36^{\prime} 48^{\prime \prime} \mathrm{N}, 7 . V I I .1998$, leg. G. Csorba \& L. Ronkay, slide No. RL11681m (coll. HNHM); 1 female, Himalaya Mts, Kaghan valley,

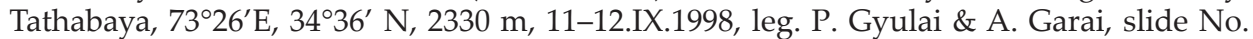
GYP4372f (coll. PGY); 3 males, Himalaya Mts, Kaghan valley, Khanyan village, 1770 m, 12-13.IX.1998, leg. P. Gyulai \& A. Garai (coll. PGY).

Diagnosis - The species can be distinguished from $D$. costigerodes by its broader forewings with less distinct, less ochreous suffused costal stripe, somewhat stronger and more sinuous antemedial and postmedial crosslines; from $D$. euxoides and $D$. jensergabori by its broader forewings with straighter and more distinct subterminal line, and weaker, less sinuous crosslines, and paler, more whitish suffused inner area with less prominent discal lunule of the hindwings.

The male genitalia of $D$. ferrisparsa (Figs 15-16) differ from those of the other two eastern Asiatic congeners (Figs 17-22; the male of $D$. jensergabori is still unknown) by the much smaller and finer bundle of spines at base of harpe, larger and more angular cucullus and the evenly arched vesica armed by very long cornuti field, covering almost the full length of the tube.

The female genitalia of $D$. ferrisparsa (Fig. 25) can be distinguished from those of $D$. costigerodes (Fig. 26) by the broader and shorter antrum, posteriorly more dilated ductus bursae with longer ribbed area anteriorly, and by the much longer sclerotised inner curve of appendix bursae; the differences 
between these two species and the newly described Chinese ones are given under the Diagnosis of $D$. costigerodes.

The specific differences between them are found in the size and shape of these features: $D$. costigerodes has more elongated antrum, less dilated posterior end and shorter but more densely ribbed anterior section of ductus bursae and the appendix bursae is only basally ribbed, without sclerotised area in the medial part of its inner curve.

Distribution - Southern Himalayan. It has been recorded from Pakistan, India, Nepal and Bhutan.

\section{Dicerogastra euxoides sp. $\mathrm{n}$.}

(Figs 7-10, 19-22, 27-28)

Holotype, male (Figs 7-8), China, North Yunnan, Diqing Tibetan Autonomous Prefecture, $5 \mathrm{~km} \mathrm{~S}$ of Deqin, $3356 \mathrm{~m}$, 19.VI.2009, leg. B. Benedek, slide No. GYP2333m (coll. PGY).

Paratypes. China. 2 males, with the same data as the holotype; (coll. PGY); 1 male, from the same locality as the holotype, 16-17.VI.2009 (coll. G. Ronkay); 1 male, North Yunnan, Diqing Tibetan Autonomous Prefecture, $8 \mathrm{~km}$ NNE Shangri La at Nairi village, 3300 m, 14.VI.2009, leg. B. Benedek (coll. PGY); 1 female, Sichuan, $100 \mathrm{~km} \mathrm{~W}$ of Maniganggo, 3400 m, 26.VI.2004, leg. S. Nykl, slide No. GYP1894f (coll. PGY); 2 males, 4 females, Yunnan, Deqin, 3400 m, N28 $30^{\prime}$, E98 $55^{\prime}$, 30.V.-3.VI.2011, leg. J. Klir, slide No. GYP3952m (coll. M. Dvoř́k); 2 males, from the same locality, slide Nos RL11273m, RL11274m (coll. L. Srnka).

Diagnosis - Wingspan 32-34 mm, length of forewing 14-16 mm. Vestiture of the head and body, ground colour of wings various shades of brown, costal margin and apical patch somewhat lighter, antemedial and postmedial crosslines whitish, subterminal line pale whitish-ochreous; orbicular stigma tiny, circular, reniform stigma elliptical, both stigmata brown, latter incompletely whitish encircled; claviform stigma dark brown.

The new species (Figs 7-10) differs from the externally most similar $D$. ferrisparsa (Figs 1-2) by its paler ground colour, particularly in the females, more distinctly marked and somewhat differently shaped antemedial and postmedial crosslines, more sinuous and less distinctly marked subterminal line, and the somewhat darker hindwing inner area with stronger marked, lunulate discal spot.

Dicerogastra euxoides is easier distinguished from the other Himalayan species, D. costigerodes (Figs 3-6) by its smaller size (wingspan $32-34 \mathrm{~mm}$ and 37-39 $\mathrm{mm}$, respectively), much less prominent forewing costal stripe and whitish defined antemedial and postmedial crosslines, the more sinuous and less sharply marked subterminal line and, last but not least, by the almost unicolorous brown hindwing with well-visible dark cellular lunule. The differential diagnosis of $D$. euxoides and $D$. jensergabori is given under the Diagnosis of the latter species. 
Male genitalia (Figs 19-22) - Comparing the male clasping apparatuses of the three closely related species, D. euxoides has the smallest cucullus, largest and most ventro-apically projected ampulla, and the longest spines at base of harpe. Additionally, the vesica of D. euxoides is armed by very short, terminally positioned cornuti field whereas it is much longer in the other two species and never located at the posterior end of the vesica.
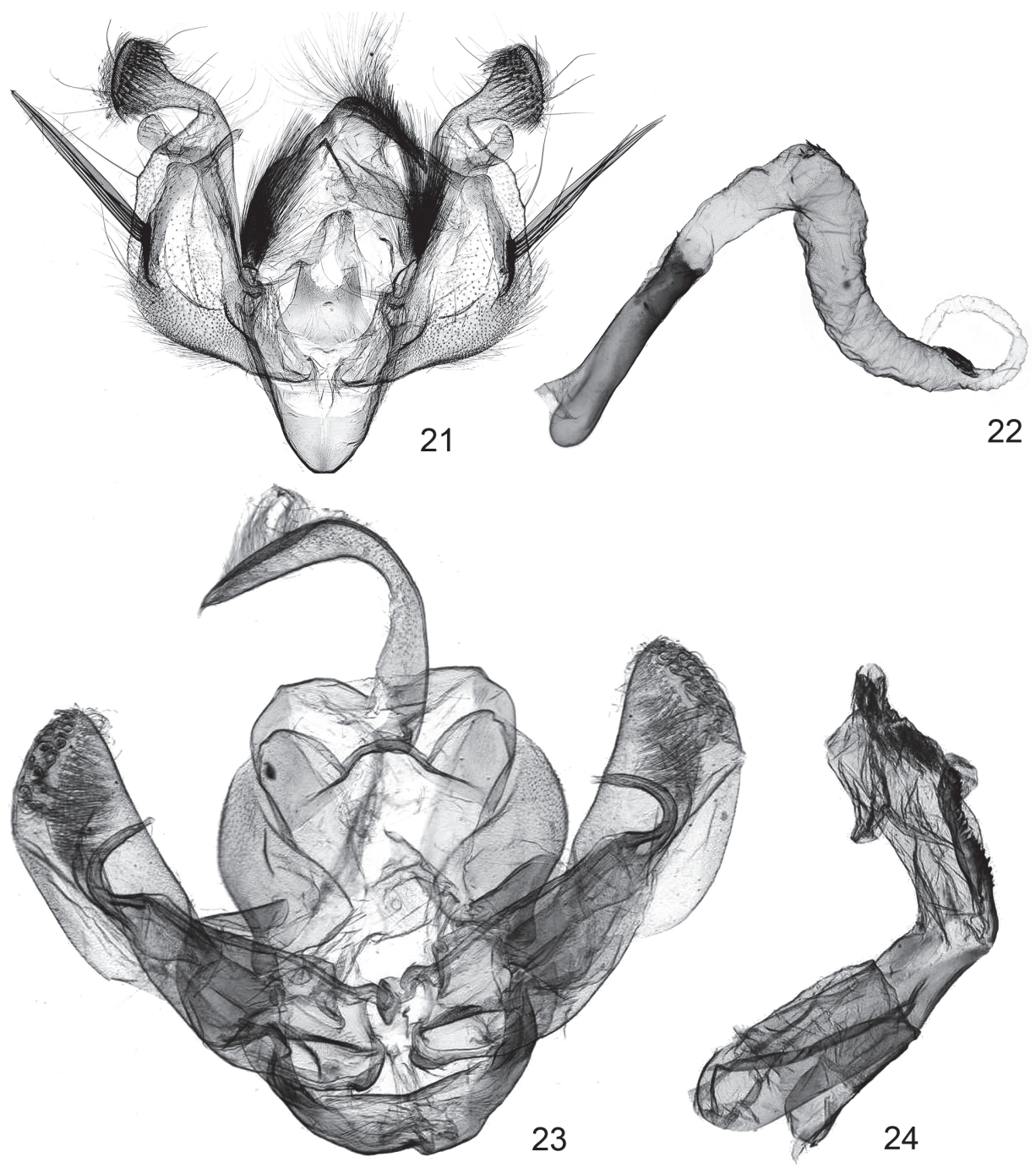

Figs 21-24. Male genitalia of Dicerogastra and Feliniopsis species. 21-22 = D. euxoides sp. n., paratype, RL11274m, 21 = clasping apparatus; 22 = aedeagus; 23-24 = Feliniopsis albiflexura

(Walker, 1857), holotype, BM Noct. 15787m, 23 = clasping apparatus; 24 = aedeagus 
Female genitalia (Figs 27-28) - The female genitalia of D. euxoides differ from those of $D$. jensergabori by the lack of sclerotisation from the distal part of appendix bursae and the somewhat shorter, medially more sclerotised ductus bursae; the differences between D. euxoides and the two southern Himalayan species are discussed in detail under the Diagnosis of $D$. costigerodes.

Distribution - The new species is known from the south-eastern borders of the Tibetan plateau in China, from Yunnan and Sichuan. This distribution pattern helps the correct identification, since no sympatric occurrence with the southern Himalayan species hitherto described is known.

Etymology - The specific name refers to the superficial similarity of the male genitalia with those of the Euxoa Hübner, 1821 species. The very long spine-bundle and the long penicular hair-tuft resembles in a macroscopic view the two characteristic sclerotised processes (ampulla and saccular extension) of an Euxoa clasping apparatus.

\section{Dicerogastra jensergabori sp. n.}

(Figs 11, 12, 29)

Holotype, female, China, W Sichuan, Kangding city, 3000-3500 m, 23-27.VII.2007, leg. native collector, slide No. GYP4361f (coll. PGY).

Diagnosis - Wingspan $33 \mathrm{~mm}$, length of forewing $17 \mathrm{~mm}$. Female. Pubescence of head and body and ground colour of median and terminal areas of forewing deep brown whereas costal margin, basal and subterminal fields ochreous-brown with week reddish-brown suffusion. Antemedial and postmedial crosslines dark brown, fine but well discernible, postmedial line strongly serrate; subterminal line pale ochreous, sinuous, followed by more or less continuous dark shade at inner side. Orbicular stigma tiny, black outlined, reniform stigma regularly shaped, both stigmata brown, latter one more or less strongly whitish encircled and filled; claviform stigma blackish. Hindwings almost uniformly cupreous brown with fine discal spot. Male unknown.

Dicerogastra jensergabori differs externally from its rather similar congeners, D. ferrisparsa (Figs 1-2) and D. euxoides (Figs 7-10), by its weakly dark brown suffused light ochreous-brown coloured basal and subterminal fields, more distinctly marked (but not whitish defined) and somewhat differently shaped antemedial and postmedial lines. The subterminal line is paler and more sinuous, and the hindwing is generally darker than in D. ferrisparsa. The separation from $D$. costigerodes (Figs 3-6) is much easier, due to its smaller size (33 $\mathrm{mm}$ and 37-39 $\mathrm{mm}$, respectively), shorter forewing apex, darker and less prominent costal stripe, deep brown suffusion in basal and marginal fields, and the rather unicolorous brown hindwings with well-visible dark cellular spot.

The female genitalia of $D$. jensergabori (Fig. 29) can be distinguished from those of its closest relative, D. euxoides, by the conspicuous, strongly sclerotis- 


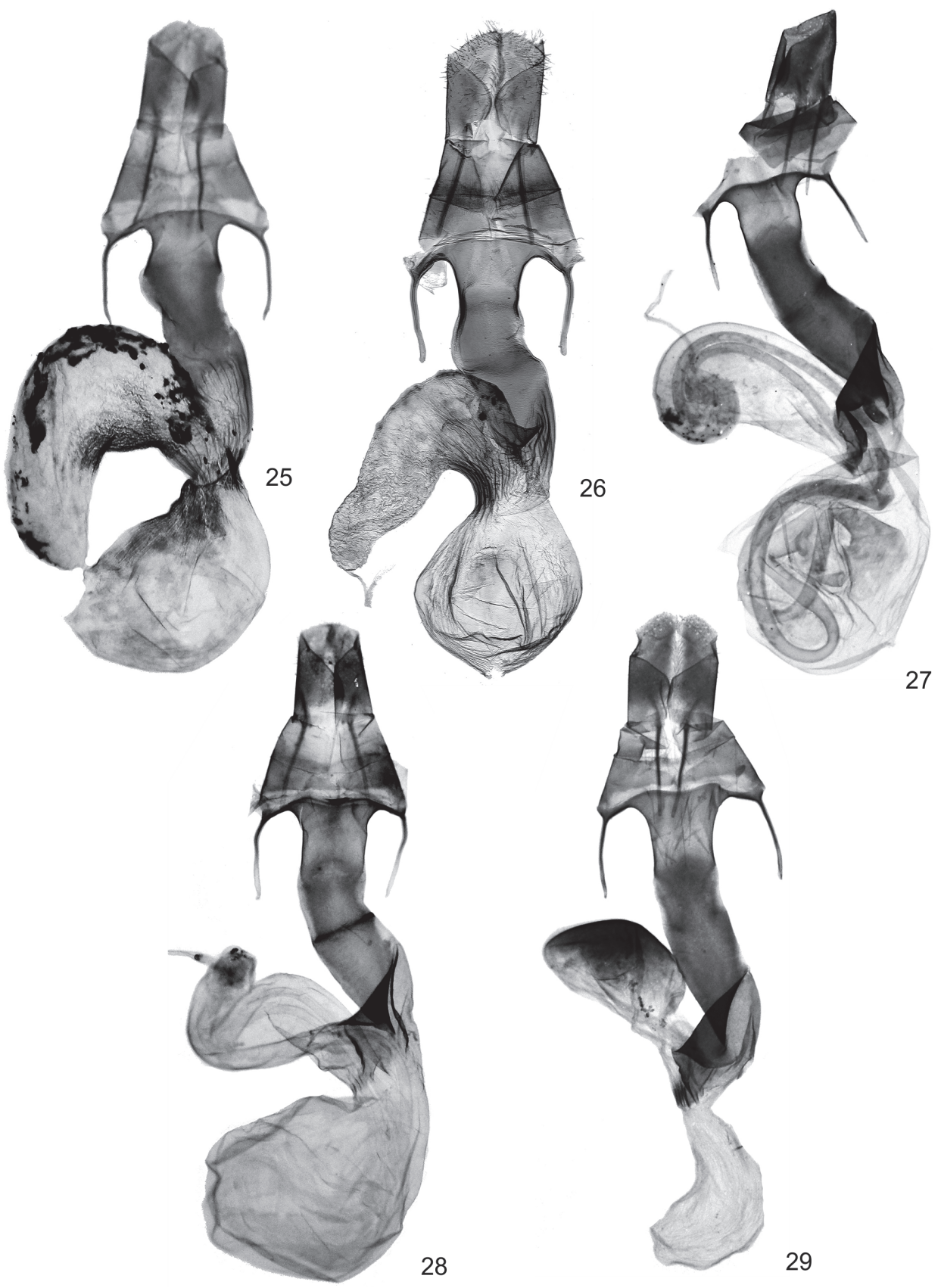

Figs 25-29. Female genitalia of Dicerogastra species. 25 = Dicerogastra ferrisparsa (Hampson, 1894), GYP4354f; 26 = D. costigerodes (Poole, 1989), lectotype, BM Noct. 15514f; $27=$ D. euxoides sp. n., paratype, GYP1894f; $28=$ D. euxoides sp. n., paratype, GYP4391f; $29=D$. jensergabori sp. n., holotype, GYP4361f 
ed surface of the distal part of appendix bursae, this feature is unique within the eastern Asiatic members of the genus (see Figs 25-29).

Bionomics and distribution - Sino-Tibetan. The new species is known from the type locality (China, Sichuan) only, by a single female; accordingly no sympatric occurrence with $D$. euxoides is known.

Etymology - The new species is dedicated to the late Dr Gábor Jenser, famous expert of Thysanoptera.

Acknowledgements - The authors are grateful to Lubos Srnka (Slovakia) and Marek Dvořák (Czech Republic) for loaning material and sending photos.

\section{REFERENCES}

Berio, E. (1973): Nuove specie e genere di Noctuidae Africane e Asiatiche e note sinonimichi. Parte II. Annali del Museo Civico di Storia Naturale di Genova 79: 126-171.

Fletcher, D. S. (1961): Noctuidae. In: Evans, G. O. \& Fletcher, D. S. (eds): Ruwenzori Expedition. 1952(7): 177-323.

Hacker, H. (1992): Systematik und Faunistik der Noctuidae (Lepidoptera) des himalayanischen Raumes. Beitrag II. Esperiana 3: 67-234.

Hampson, G.F. (1902): The moths of South Africa (Part II). Annals of the South African Museum 2: $255-446$.

Hampson, G.F. (1913): Descriptions of new genera and species of Noctuidae. - Annals and Magazine of Natural History (8)12: 580-601. https://doi.org/10.1080/00222931308693446

Hreblay, M. \& Ronkay, L. (1998): Noctuidae from Nepal. - In: Haruta, T. (ed.): Moths of Nepal, Vol. 5. Tinea 15(Suppl. 1): 117-310.

Poole, R. W. (1989): Noctuidae. In: Heppner, J. B. (ed.): Lepidopterorum Catalogus, New Series. Fascicle 118. E. J. Brill Flora and Fauna Publication, New York, 1314 pp.

Viette, P. (1972): Les Noctuelles trifides du Massif de l'Andingitra (Madagascar Centre) (Lep.). Annales de Sciences naturelles, Zoologie et Biologie animale (12) 14(2): 147-176.

Wiltshire, E. P. (1956): Middle East Lepidoptera, XIII: Two new species from Jordan. The Entomologist 89: 237-240.

Received January 11 , 2016, accepted May 13, 2016, published March 3, 2017 